\title{
ANALYSIS OF THIN FILM FIRE SENSORS ${ }^{\dagger}$
}

\author{
G. ZENTAI and ZS. ILLYEFALVI-VITÉZ \\ Technical University, Budapest, Hungary \\ (Received November 1, 1982; in final form June 6, 1983)
}

\begin{abstract}
The detection of fire in mines, industrial buildings, ships etc. is an important problem from both the economical and life-protecting aspects. The fire could be detected in several ways, e.g. by the measurement of flame-radiation, heat, pressure, temperature, the aerosols, the gases etc.

The Department of Electronic Technology has developed a fire sensor which detects the rate of the increase of temperature. The fire sensor consists of two temperature sensitive resistors with different time-constants. If the increase of temperature in consequence of the fire is fast, the difference between the resistance of the temperature sensors is high, while a slow change in temperature causes only small differences. By connecting the temperature sensitive sensors into a bridge, the resistance difference can be easily detected.

The temperature sensitive resistors are realized by thin film technology using platinum or nickel film on a thin glass or ceramic substrate. Because of the large surface and small volume of the resistor, its time-constant originally is very low but the time-constant could be easily increased by increasing the volume of the resistor. The present paper gives a detailed description of the analysis and the measurement of the temperature sensitive resistors with different time-constants. The technology of the films is also discussed.
\end{abstract}

\section{INTRODUCTION}

The detection of fire in mines, industrial buildings, ships etc. is an important problem from both economical and life-protecting aspects. The fire could be detected by several methods and the selection of the proper sensor depends on the character of the fire which may have occurred. The following methods of detection are used ${ }^{1,2}$ :

- Combustion products detectors which operate when particles enter an ionization chamber.

- Photoelectric cells which operate when a light source is scattered by smoke particles.

- Photoelectric cells which operate when a light source is obscured by smoke.

- Heat detectors which operate when the rate of rise of air temperature exceeds a preset rate.

- Heat detectors which operate when the air temperature rises above a preset level.

- Infra red heat detectors which sense radiated heat from flames.

- Ultra violet detectors which sense the light radiated by flames in the higher end of the light spectrum.

Some detector heads combined more than one of the above mentioned methods. The head is always completed by an electronic control system, which indicates the change of the sensor and protects against typical unexpected faults e.g. short circuit, break etc.

\section{THE THIN FILM FIRE SENSOR}

The fire detector head developed by the Department of Electronics Technology belongs to the group of rate of temperature rise sensors.

\footnotetext{
† Paper originally presented at the 5th International Spring Seminar on Electrotechnology held at Prenet
} Czechoslovakia, 1-4 June, 1982. 
The detector comprises two temperature sensors, each having a different thermal inertia, so the difference between the outputs of the sensors is proportional to the rate of the temperature rise. When a slow change in air temperature occurs, the two sensors register the same temperature and no alarm is given. If a rapid change occurs, the sensor having the slower response registers a lower temperature than the faster one. When this temperature difference exceeds a predetermined value, the alarm operates.

This type of detector is suitable for protecting enclosed areas in machinery buildings where the height of the room is not very great. The internal parts of the head can be sealed within the unit, thus it can be used in a dirty environment and requires little maintenance.

The temperature sensors used in fire detectors would be bimetal strips, temperature sensitive resistors, thermocouples, thermistors etc. In our fire detector head temperature sensitive resistors are used in metal thin film form deposited onto glass substrates. Due to the high temperature coefficient of the platinum or nickel thin metal film the sensors have the required sensitivity and they have the advantage of good stability and high reliablity too.

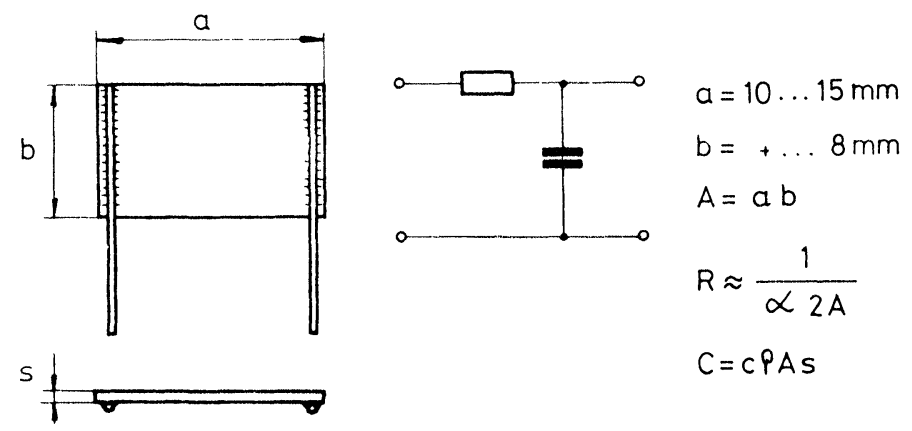

FIGURE 1 The model of a thin film sensor.

In it simplest construction (Figure 1.) the temperature sensitive thin film resistor has only two thin copper wire leads soldered to the both ends of the rectangle shaped substrate covered by the platinum or nickel film. The sensor is protected against the environmental conditions by a thin epoxy- or silicon-resin layer. In this form the behaviour of the sensor could be written by the formulas of an $\mathrm{RC}$ circuit. The $\mathrm{R}$ heat resistance determined by the heat transmission characteristics of the surface $A_{s}$ of the sensor, while the heat capacitance $\mathrm{C}$ by the mass $\mathrm{m}$ and the specific heat capacitance $\mathrm{c}$ of it:

$$
\begin{aligned}
& \mathrm{R}=1 / \alpha \mathrm{A}_{\mathrm{s}} \approx 1 / 2 \alpha \mathrm{A} \\
& \mathrm{C}=\mathrm{cm}=\mathrm{c} \rho \mathrm{V}=\mathrm{c} \rho \mathrm{As} \\
& \mathrm{T}=\mathrm{RC} \approx \mathrm{c} \rho \mathrm{s} / 2 \alpha \mathrm{A}
\end{aligned}
$$

where $\alpha$ is the heat transmission coefficient of the surface; $\mathrm{A}$ is the surface of the rectangle of the sensor; $\rho$ is the density of the glass substrate; $s$ is the thickness of the substrate; and $\mathrm{T}$ is the time-constant of the sensor. These and some other parameters for the materials used in the construction are featured in Table I. It could easily be shown that the heat resistance of the substrate perpendicularly to the surface is much smaller than the heat transmission resistance (R); the heat conducted away by the wire leads is small because the wires heated directly by the air can warm the substrate; the effect of the thin sensitive film and the protective layer on the heat capacitance of the sensor is very small because these layers are very thin, so these effects are ignored. 
Table I.

The parameters of the sensors

\begin{tabular}{llll}
\hline Number & 1. & 2. & 3. \\
\hline Encapsulated & no & no & yes \\
$\mathrm{s}(\mathrm{mm})$ & 0.4 & 0.8 & 0.8 \\
$\alpha\left(\mathrm{WK}^{-1} \mathrm{~m}^{-2}\right)$ & 25 & 25 & 12 \\
$\lambda\left(\mathrm{Wm}^{-1} \mathrm{~K}^{-1}\right)$ & glass: $\quad 1 \quad$ glass: $\quad 1 \quad$ epoxi: 0.09 \\
$\rho\left(\mathrm{kgm}^{-3}\right)$ & glass: 2.7 & glass: 2.7 & epoxi: 1.3 \\
$\mathrm{c}\left(\mathrm{Jkg}^{-1} \mathrm{~K}^{-1}\right)$ & glass: 750 & glass: 750 & epoxi: 1500 \\
$\mathrm{~A}_{\mathrm{s}}\left(\mathrm{m}^{2}\right)$ & $6.10^{-5}$ & $6.10^{-5}$ & $6.10^{-4}$ \\
$\mathrm{~T}_{1} ; \mathrm{T}_{2} ; \mathrm{T}_{3}(\mathrm{~s})$ & $16.5 ;-;-$ & $33 ;-;-$ & $135 ; 4 ; 18$ \\
\hline
\end{tabular}

In this case the $r$ change of the resistance of the sensor can be written in the following form, if the environmental temperature $(\vartheta)$ changes as a unit jump with $\theta$ temperature difference:

$$
\mathrm{r}=\mathrm{k} \theta[1-\exp (-\mathrm{t} / \mathrm{T})],
$$

where $\mathrm{k}$ is the temperature coefficient of the resistance and $\mathrm{t}$ is the time.

If the temperature changes linearly with a constant rate of $\omega$, the resistance changes as follows:

$$
\mathrm{r}=\mathrm{k} \omega[-\mathrm{T}+\mathrm{t}+\mathrm{T} \exp (-\mathrm{t} / \mathrm{T})]
$$

Figure 2 shows the changes of the input and output parameters in both cases.
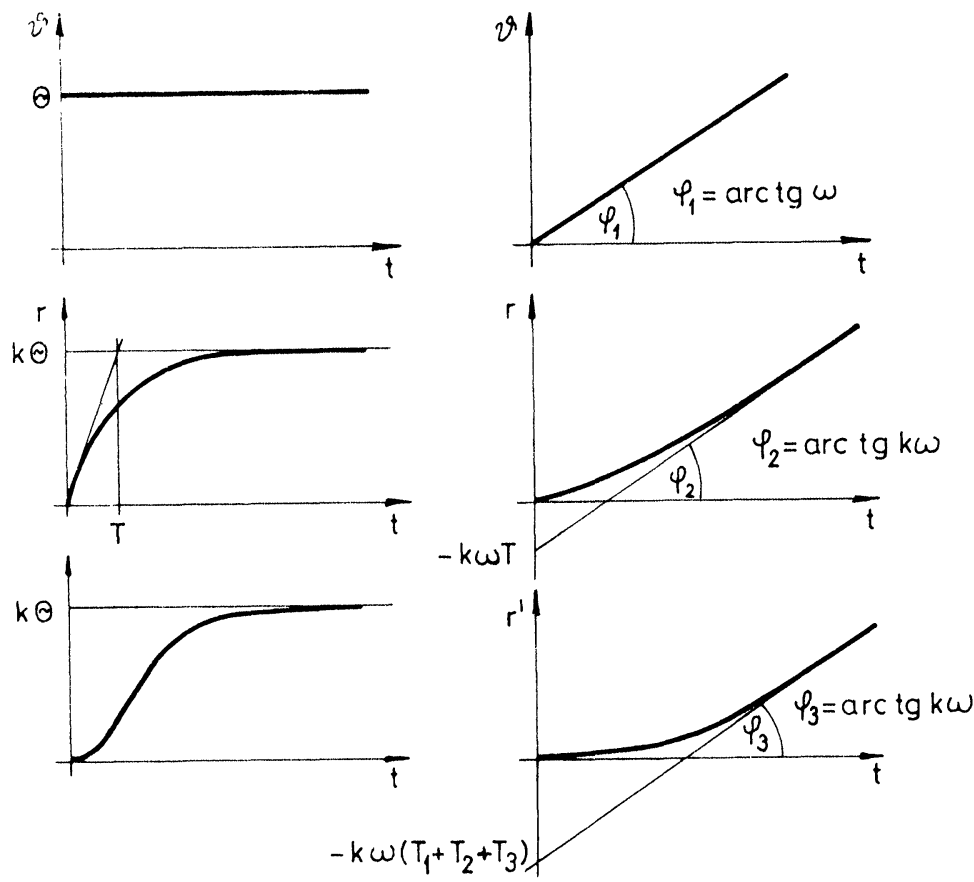

FIGURE 2 Behaviour of thin film sensors 

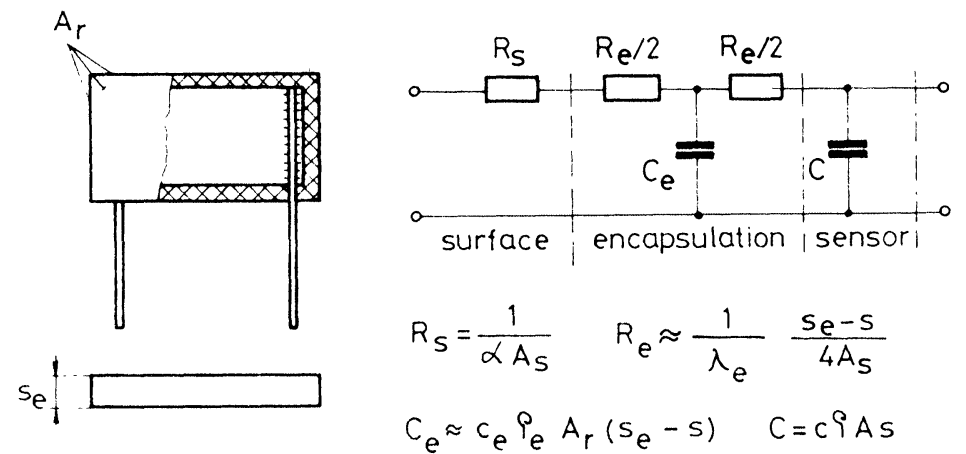

FIGURE 3 The model of a delayed sensor

To make a delayed sensor with different thermal inertia the simplest way to delay it is by encapsulation. A physical model describing the behaviour of a delayed sensor and the meaning of the terms used is shown in Figure 3.

Let us assume the following:

$$
\begin{aligned}
& \mathrm{R}_{1}=\mathrm{R}_{\mathrm{s}}+\mathrm{R}_{\mathrm{e}} / 2, \mathrm{C}_{1}=\mathrm{C}_{\mathrm{e}}, \mathrm{R}_{2}=\mathrm{R}_{\mathrm{e}} / 2, \mathrm{C}_{2}=\mathrm{C}, \\
& \mathrm{T}_{1}=\mathrm{R}_{1} \mathrm{C}_{1}, \mathrm{~T}_{2}=\mathrm{R}_{2} \mathrm{C}_{2}, \mathrm{~T}_{3}=\mathrm{R}_{1} \mathrm{C}_{2}, \\
& \mathrm{~s}_{1,2}=\left[-\left(\mathrm{T}_{1}+\mathrm{T}_{2}+\mathrm{T}_{3}\right) \pm \sqrt{\left(\mathrm{T}_{1}+\mathrm{T}_{2}+\mathrm{T}_{3}\right)^{2}-4 \mathrm{~T}_{1} \mathrm{~T}_{2}}\right] / 2 \mathrm{~T}_{1} \mathrm{~T}_{2} \\
& \mathrm{~A}=1 / \mathrm{s}_{1}+1 / \mathrm{s}_{2}, \mathrm{~B}=\mathrm{s}_{2} / \mathrm{s}_{1}\left(\mathrm{~s}_{1}-\mathrm{s}_{2}\right), \mathrm{D}=-\mathrm{s}_{1} / \mathrm{s}_{2}\left(\mathrm{~s}_{1}-\mathrm{s}_{2}\right) .
\end{aligned}
$$

The change of the resistance of the sensor (Figure 3), if the input signal is a temperature jump is

$$
\mathrm{r}^{\prime}=\mathrm{k} \theta\left[1+\mathrm{Bs}_{1} \exp \left(\mathrm{s}_{1} \mathrm{t}\right)+\mathrm{Ds}_{2} \exp \left(\mathrm{s}_{2} \mathrm{t}\right)\right]
$$

and if the input signal is a temperature change with constant rate:

$$
\mathrm{r}^{\prime}=\mathrm{k} \omega\left[\mathrm{A}+\mathrm{t}+\mathrm{B} \exp \left(\mathrm{s}_{1} \mathrm{t}\right)+\mathrm{D} \exp \left(\mathrm{s}_{2} \mathrm{t}\right)\right]
$$

If the difference of the changes of two sensors with different thermal inertia is needed, we have to form the difference of either equations (1) and (3) or (2) and (4) depending on the form of the input signal.

\section{RESULTS}

The temperature sensitive thin platinum and nickel films were made by evaporation from an electron beam evaporation source on a chromium adhesive film. The substrates were Corning 7059 glass sheets with $\mathrm{s}=0.4$ and $0.8 \mathrm{~mm}$ thickness. After evaporation the films were heat-treated on $300^{\circ} \mathrm{C}$ for $4 \ldots 8$ hours to achieve the desired high stability, and then sliced to the proper size. The leads were attached by softsoldering. The solderability of the platinum films was very good, so the leads could be directly soldered onto the film, while for the soldering of the nickel film sensors a gold contact layer had to be used. For this reason the platinum film sensors were preferred. Finally the sensors were protected with a very thin silicon-resin layer. Some of them were encapsulated into a small plastic case by epoxy-resin to achieve the proper delay. 


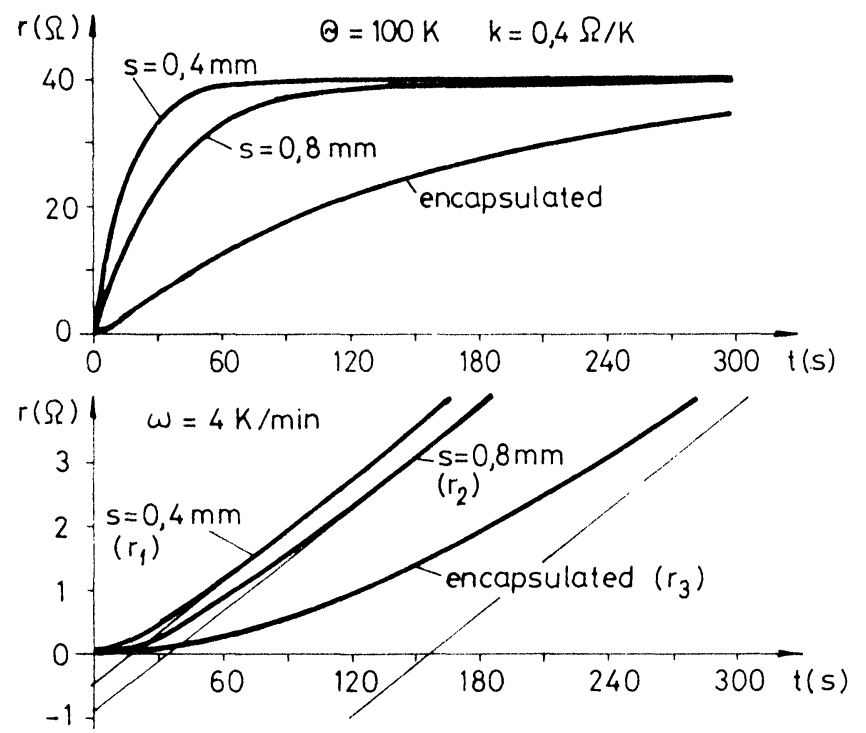

FIGURE 4 The resistance change of the sensors

It was found that the models describing the behaviour of both type sensors were quite correct, the measured and calculated characteristics ran in the same way, within $5 \%$ deviation which was about the accuracy of the measurement. Figure 4 shows the results of the measurements of three types of sensors, viz. sensors on 0.4 and $0.8 \mathrm{~mm}$ thick substrates without encapsulation and a sensor encapsulated in a plastic case. The curves in Figure 4(a) are the resistance change when the sensors were put into a fixed temperature oven, while the curves in Figure 4(b) show the change in an oven whose temperature rise ws $4^{\circ} \mathrm{C} / \mathrm{min}$.

The three types of sensors could be combined into pairs in three different ways. The resistance differences between the pairs in the oven with arising temperature are shown in Figure 5. If the demands on the detector are to warn for $4^{\circ} \mathrm{C} / \mathrm{min}$ temperature rise but not to warn for $75 \%$ of it (for $3^{\circ} \mathrm{C} / \mathrm{min}$ ), we can determine the time constants of the demands $\left(\tau_{1}, \tau_{2}\right.$ and $\tau_{3}$ in Figure 5). It will be seen that for fast detectors the pair combined from the 0.4 and $0.8 \mathrm{~mm}$ thick sensors has to be used, while if a short response time is not needed, the more solid and reliable pair combined from the thick and encapsulated sensors is offered.

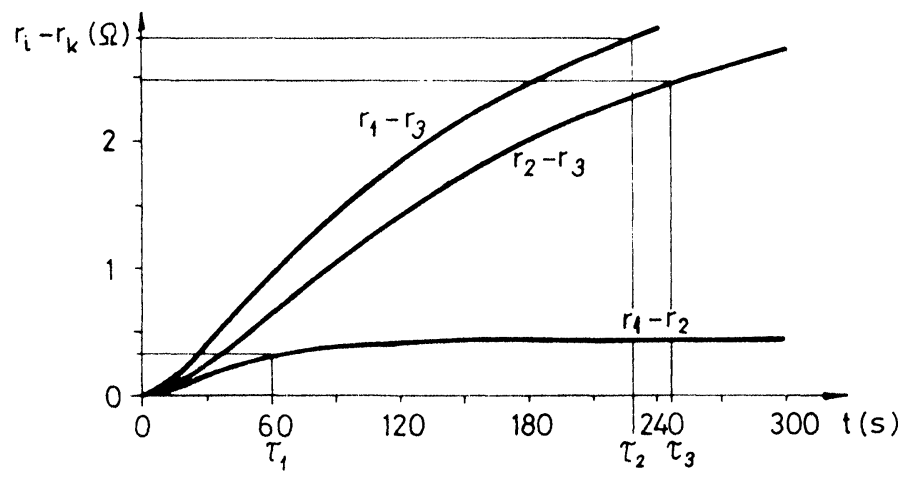

FIGURE 5 The characteristics of the fire detectors 


\section{ACKNOWLEDGEMENTS}

The authors would like to express their thanks to Mr. Vaskuti and Mr. Seefranc, the research workers of the Research Institute of the Instrument Industry for their consultative help and for the sponsorship of the work. They also thank Mr. David, student of the Faculty of Electrical Engineering for his work.

\section{REFERENCES}

1. R.G. Gowar, Modern electric fire detection devices, The Plant Engineer, 22, 20-21 September 1978.

2. J.D. Bolding, Fire Detection in Unattended Machinery Spaces, Schiff und Hafen, 2, 1975. 

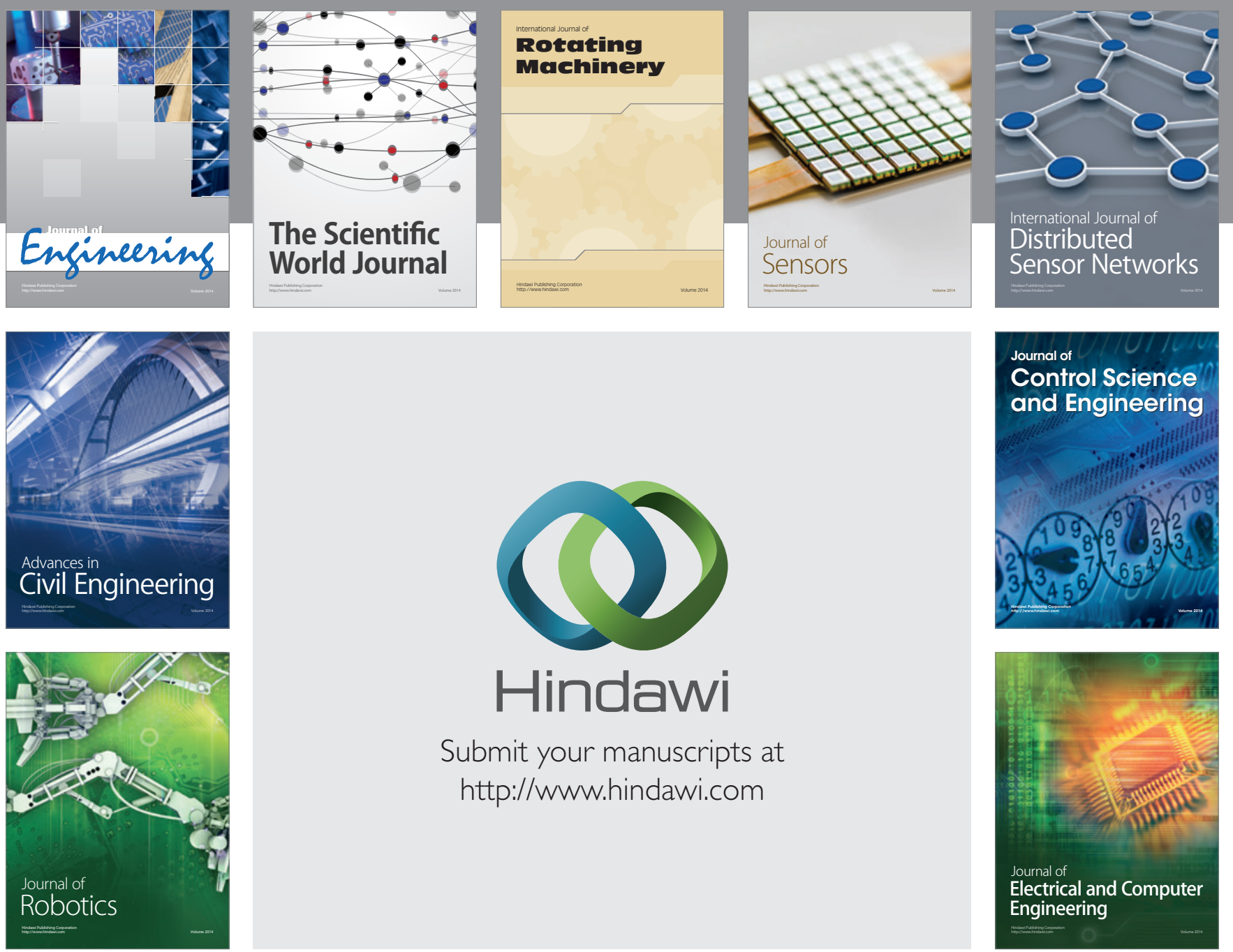

Submit your manuscripts at

http://www.hindawi.com
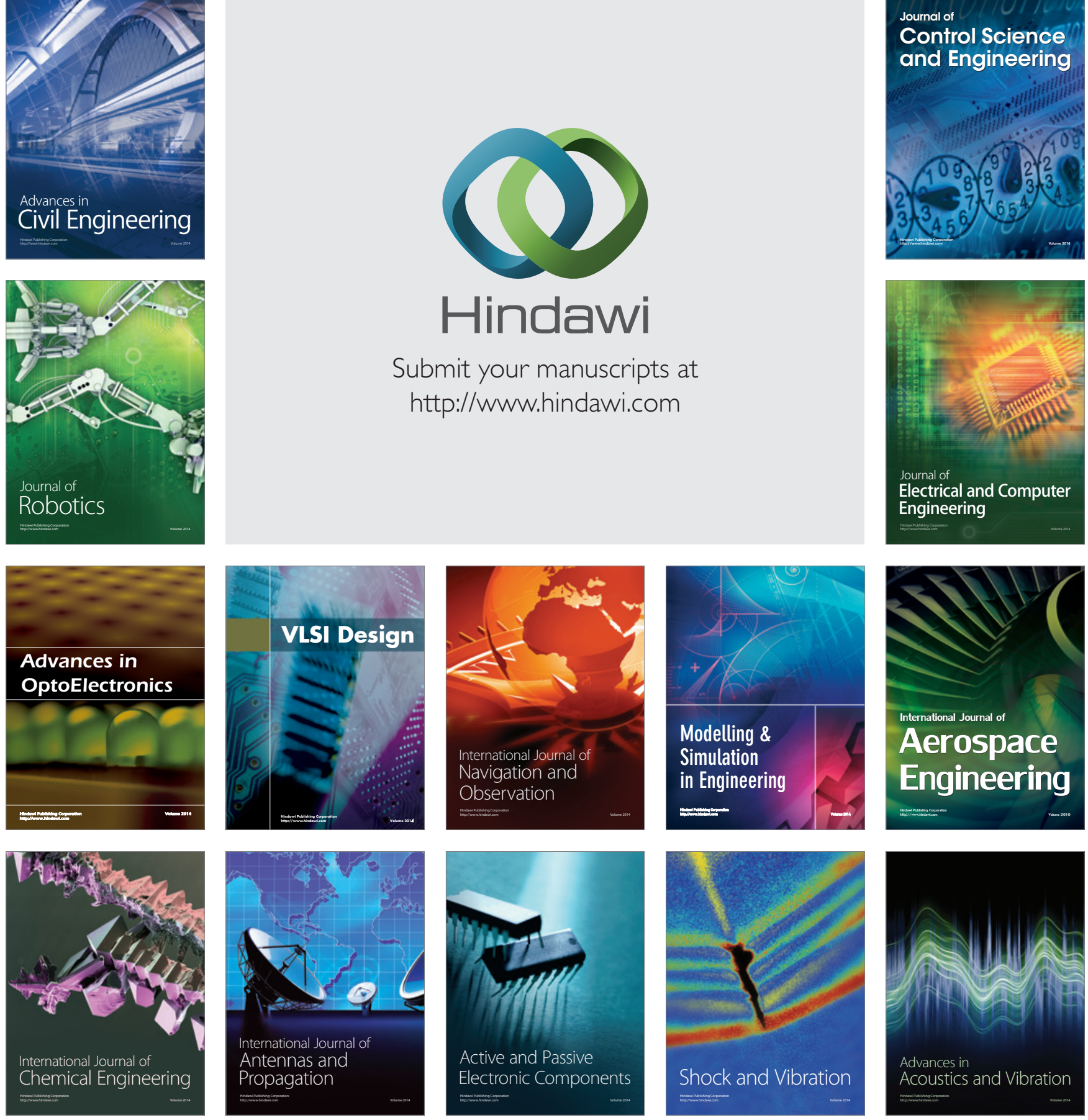